\title{
Syntheses and Structural Characterization of Triorganotin Derivatives of 3-Mercapto-4-methyl-4H-1,2,4-triazol: X-ray Crystal Structures of One-dimensional Zigzag Polymeric Chain of $\mathrm{Me}_{3} \mathrm{Sn}\left[\mathrm{SC}_{3} \mathrm{H}_{4} \mathrm{~N}_{3}\right]$ and $\mathrm{Ph}_{3} \mathrm{Sn}\left[\mathrm{SC}_{3} \mathrm{H}_{4} \mathrm{~N}_{3}\right]$
}

Chunlin Ma, ${ }^{1,2,3}$ Guangru Tian, ${ }^{1}$ and Rufen Zhang ${ }^{1}$

ERRATUM TO: JOURNAL OF INORGANIC AND ORGANOMETALLIC POLYMERS AND MATERIALS DOI: $10.1007 / \mathbf{s 1 0 9 0 4 - 0 0 6 - 9 0 4 1 - z ~}$

The submitted and accepted dates for this paper were inadvertently omitted. The dates are as follows: Submitted November 12, 2005; accepted February 4, 2006

The online version of the original article can be found at: http:// dx.doi.org/10.1007/s10904-006-9041-z

${ }^{1}$ Department of Chemistry, Liaocheng University, Liaocheng, 252059, P.R. China.

2 Department of Chemistry, Taishan University, Taian, 271021, P.R. China.

${ }^{3}$ To whom correspondence should be addressed. E-mail:macl@lctu.edu.cn 